\title{
Making it a Norm in Patient Safety
}

\author{
Harvinderjit Kaur* \\ Department of Pediatrics, University of Malaya Medical Centre, Malaysia
}

Received: 㘹: October 12, 2018; Published: 制: October 24, 2018

*Corresponding author: Harvinderjit Kaur, Department of Pediatrics, University of Malaya Medical Centre, Nursing Kuala Lumpur, Kuala Lumpur, 43300, Malaysia

\section{Opinion}

Have you come across this scenario, "Nurse why did you do it this way"? Nurse replies, "this is how it is normally done". Norm, what importance is this word to us. Norm is something that is usually, typical or standard. How can healthcare workers use this culture of norm in patient safety? How do we transform them into getting the norm attitude when complying with the guidelines and standards on patient safety? In today's healthcare system patient safety is the priority. A patient that walks into a healthcare facility would want to be and feel safe in the hand of the healthcare workers. His/her safety lies in their hands. They don't want to prolong their stay here and would like to be with their loved ones. Furthermore, longer stay means more expenses, mortality or morbidity. For the healthcare facility patients that are involved in incident on their safety means litigation, increase in expenses and workload. Focusing on improving safety culture, the focus is healthcare workers knowledge, beliefs, values, norms and behavioral character. A survey was conducted in a 52 bedded ward on nurse's compliance towards infection control guideline.

In this survey 31 nurses were assessed on their knowledge, belief and attitude toward infection control guideline. Nurse's belief that since it is does affect their performances evaluation, it did not matter if they complied or not. It is not their norm. They said there were no close monitoring from their managers and furthermore they did not read the guideline even knowing it is available. Intervention was done with education, training and implementing check list. The ward manager was the first to be given this intervention as they are going to monitor these nurses. Nurses were more aware of the importance to compliance to guideline and with the checklist it became a norm to them to follow the guideline all the time. This reduces the infection rate in that ward. They were monitored using a checklist and randomly questioned regarding the guideline. Fear of being question and unable to answer made the nurses open up the guideline and read it. It is important to make it a norm in order to prevent infection in the ward.

Similar study conducted by Brig Abhijit Chakravarty et. al. [1] showed that safety culture is low and there should be a safety culture developed in hospital for future patient safety. Ward managers too need to play their role efficiently. They should roll up their sleeves and focus on patient safety. The should make it a norm to conduct root cause analysis on incidents occur that compromise patient safety. Ward managers should instill the culture of safety into all nurses and make it a norm. Florence Nightingale known as Mother of Modern Nursing said "do the sick no harm". Nurses should be reminded on this message we healthcare workers must remember that we should not do harm to patients.

\section{Conclusion}

In conclusion patient's safety should be included in all nursing curriculum and for all healthcare workers that joins in the clinical area should be given full orientation regarding patient's safety and compliance to the guideline. Make it a norm in the healthcare workers daily activities regarding patient safety.

\section{References}

1. Abhijit Chakravarty, Brig, Anupam Sahu, Maj, Manash Biswas, et al. (2015) A study of assessment of patient safety climate in tertiary care hospitals. Medical Journal Armed Forces India 71(2): 152-157. 
ISSN: 2574-1241

DOI: 10.26717/BJSTR.2018.10.001934

Harvinderjit Kaur. Biomed J Sci \& Tech Res

(c) (1) This work is licensed under Creative

Submission Link: https://biomedres.us/submit-manuscript.php

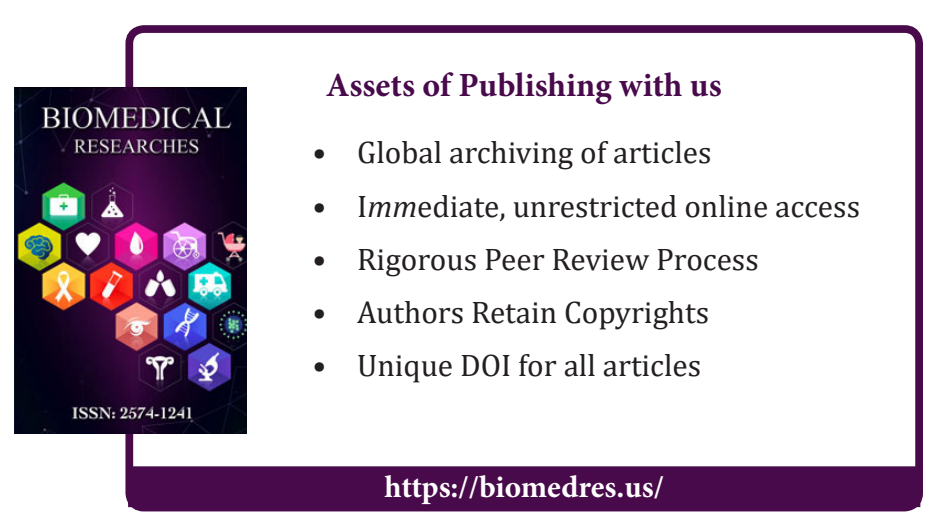

